\section{Article}

\author{
Doi 10.5943/mycosphere/5/6/12
}

ISSN 20777019

Mycosphere

Online Edition

\title{
The response of myxogastrids to soil amendments
}

\section{Feest $\mathbf{A}^{1}$ and Stephenson $\mathbf{S L}^{2}$}

\author{
${ }^{1}$ University of Bristol, Faculty of Engineering, Queen's Building, Bristol BS8 1TR and Ecosulis ltd. The Rickyard, \\ Newton St Lo, Bath, BA2 9BT, United Kingdom \\ ${ }^{2}$ Department of Biological Sciences, University of Arkansas, Fayetteville, Arkansas 72701
}

Feest A, Stephenson SL 2014 - The response of myxogastrids to soil amendments. Mycosphere 5(6), 821-829, Doi 10.5943/mycosphere/5/6/12

\begin{abstract}
Myxogastrids (also referred to as myxomycetes or plasmodial slime moulds) are common to abundant organisms in soils, where they probably account for $\sim 50 \%$ of the protozoan component represented by soil amoebae. In the present study, an effort was made to assess the possible effects of various soil amendments on myxogastrids, which exemplify the role of soil protozoans while also being relatively easy to quantify in soil samples. Amendments to soil in either field or microcosm experiments included the addition of water, glucose, a bacterial suspension and the herbicide Dalapon. Both trophic forms and encysted forms of myxogastrids were considered. As general observation, the responses of myxogastrids to the various amendments were distinct in the case of the herbicide, with the most obvious effect being the ratio of trophic to encysted forms. Any assessment of soil protozoans invariably will result in occasions where the population is grossly underestimated if samples are not tested after freezing as well as fresh. Frozen samples provide data on the total encysted population, which appears to "awakened" by the action of freezing.
\end{abstract}

Keywords - amoebae - ciliates - encystment - herbicides - soil protozoans

\section{Introduction}

The myxogastrids (also referred to as myxomycetes or plasmodial slime molds) are common to abundant organisms in soils (Stephenson \& Feest 2012, Stephenson \& Cavender 1996), where they probably account for $\sim 50 \%$ of the protozoan component represented by soil amoebae (Urich et al. 2008, Stephenson et al. 2011, Kamono et al. 2013, Stephenson \& Feest 2012). The ecological role of soil protozoans as regulators of nutrient cycling has been studied by a number of biologists (e.g., Anderson et al. 1978, Cole et al. 1978, Coleman et al. 1978a, 1978b, Clarholm 1985). Regulation by these organisms appears to be robust, functioning well in all conditions except drought, when plants cease growth and are insensitive to a reduction in their nutrient supply. It is important to understand the functional aspects of protozoans in soils and even more importantly their susceptibility to herbicides in view of the potential effects this would have both on soil fertility. Moreover, the possible role that soil protozoans may play in the control of plant diseases (Chakroborty \& Old 1982, Feest \& Campbell 1986) also warrants investigation.

Feest \& Campbell (1986), Feest \& Madelin (1985a, 1985b, 1986a, 1986b), Kerr (1994), Urich et al. (2008) and Kamono et al. (2013) have shown that suitable methods for the quantitative study of soil protozoans now exist. Moreover, they demonstrated (1) that myxogastrids exemplify 
well the role of protozoans in soil microbiocoenoses and (2) that these organisms are present in virtually all soils, being particularly abundant in fertile arable soils.

There is limited evidence relating to the susceptibility of soil protozoans to herbicides, with only 20 papers on the subject having been published since 1973 . These papers cover a wide range of herbicides but generally in only a relatively superficial manner. Thus, in only three of the papers (Foissner 1997, Gupta \& Germida 1988, Petz \& Foissner 1989) was the degree of encystment of the protozoan population actually measured. Petz \& Foissiner (1989) and Foissner (1997) tested only for encysted testate amoebae, which represent only a relatively small proportion of the total protozoan component of soils. Three other papers (Colinas et al. 1994, Ekelund 1999, Yeates et al. 1991) referred to encystment as a feature of the organisms under consideration but did not measure this phenomenon. In two additional papers (Gel'ser-Ju \& Geptner 1976, Ingham \& Coleman 1984), the authors compared numbers of amoebae and flagellates without acknowledging the existence of amoeboflagellates, and not a single paper referred specifically to myxogastrids, despite the ease with which they can be enumerated (Feest \& Madelin 1985a) and their demonstrated importance in the soil microhabitat (Feest 1987). As such, it would seem that much of the previous work needs reappraisal to consider both (1) the effect that encystment might impose on the interpretation of the results and (2) the consequences of including assessment of myxogastrids as a separate group.

The primary objective of this paper is to describe the use of simple methods to illustrate the response of soil protozoans, as exemplified by myxogastrids, to various types of soil amendments. The experiments described herein were designed to increase our understanding of encystment dynamics, which in turn would allow a more accurate interpretation of the effect of soil amendments on soil protozoa. In these experiments, encystment was recorded as the ratio of myxogastrid amoeboflagellates recorded in fresh soil to the number recorded in soil that had been frozen.

\section{Materials \& Methods}

Field Experiment: The site used in this part of the project was an apple orchard on a shallow red marl soil at the Long Ashton Research Station at Bristol in the United Kingdom, which had been used previously (Feest \& Madelin 1985a, 1986b, Feest 1987) for experiments involving myxogastrids. The grass sward at the Station was mowed occasionally and the grass cuttings left in place. During the experiment described below, the weather was warm, with daytime temperatures being around $20^{\circ} \mathrm{C}$. No rain fell during this period, and the soil was hard and dry.

Treatments were applied to four 1.0 by $1.0 \mathrm{~m}$ non-replicated plots, and all samples (50 cores, each $1 \mathrm{~cm}^{2}$ ) were collected from the top $4 \mathrm{~cm}$ of the soil profile as described by Feest \& Madelin (1985b). Consequently, the total volume of soil taken from each plot was $50 \times 4 \mathrm{~cm}^{2}$ and, after crumbling and mixing the soil, dilution series were set up for both the fresh soil and soil which had been rapidly frozen overnight. Replication of the plots was not used since replication was inherent in the sampling procedure (Feest \& Madelin 1985b). Treatments applied to the plots were (1) none, with the plot left as an untreated control, (2) watered evenly with 10 liters of sterile water, (3) watered evenly with 10 liters of sterile $1 \% \mathrm{w} / \mathrm{v}$ dextrose solution and (4) watered evenly with 10 liters of a bacterial suspension prepared in the manner described below.

First, an isolate of Serratia marcesens, obtained from a soil sample collected at the Long Ashton site, was grown in nutrient broth (Oxoid Ltd., Basingstoke, United Kingdom) for $24 \mathrm{hr}$, washed by centrifugation three times in distilled water and adjusted to a final concentration of $5 \mathrm{x}$ $10^{9}$ cells $\mathrm{ml}^{-1}$ as determined by a plate count. Serratia marcesens was used because its colony is easy to distinguish from those of the rest of the soil bacterial population, this species is relatively rare in soil and it is highly digestible to soil protozoans. Plots were sampled immediately before the soil treatment and then daily for three days.

Microcosm Experiment: Soil from the field site was used was used to prepare a series of microcosms. The turf layer $(\mathrm{ca} 5 \mathrm{~cm}$ ) was removed and the top $20 \mathrm{~cm}$ of the exposed soil profile was collected, mixed and placed in wooden boxes (each $1 \mathrm{~m} \times 1 \mathrm{~m} \times 0.5 \mathrm{~m}$ ) which were left undisturbed in the open for five weeks before treatment. All weed seedlings were removed by hand 
as they appeared. Treatments applied to the microcosms were (1) none, with the microcosm serving as an untreated control, (2) sprayed with water, and both (3) and (4) sprayed with the herbicide Dalapon (2,2-dichloropropionic acid, used as the sodium salt in a formulation containing $72 \%$ acid equivalent; Boots Dalapon Weedkiller, Boots Farm Sales Ltd., Nottingham, United Kingdom) at 4.0 (treatment 3) or 40 (treatment 4) $\mathrm{kg} \mathrm{ha}^{-1}$. The Dalapon and water treatments were applied at 375 liters per $\mathrm{ha}^{-1}$, the recommended application volume for this herbicide, using an Oxford Precision knapsack sprayer. The boxes were allowed to stand for three weeks and the treatments were then repeated.

The first soil samples were taken (Feest \& Madelin 1985b) from each box the day before the second treatment and further samples were taken daily for four days, with a final sampling carried out 11 days after the second treatment. Protozoan populations in field and microcosm soils were assessed both in fresh samples and in duplicate samples that had been stored frozen for 3 days at $-20^{\circ} \mathrm{C}$ and thawed immediately prior to the assessment (Feest \& Madelin 1985a). Trophic forms of protozoans are destroyed by fast freezing, so this treatment provided a count of cysts and spores, which are not so destroyed but rather stimulated by freezing to excyst (Feest 1987). Myxogastrid spores are not abundant in soil (Feest, unpublished data) and their very small contribution to the cyst count can be ignored. As noted earlier, data are expressed as the ratio of the numbers in fresh soil that had not been frozen to those present in soil that had been frozen (i.e., the ratio of total protozoans to encysted protozoans [T/C], which is herein designated as the 'encystment index').

Myxogastrid amoeboflagellates were identified as present on a dilution plate by microscopic examination on the basis of their typical, slim, pyriform shape and conical anterior bearing a single free flagellum (a second, closely appressed flagellum present in amoeboflagellates is normally difficult to see without special preparation) and their characteristic wobbling motion in the free fluid on the agar plate (Taylor 1987). Amoeboid non-flagellate forms lack any distinct characteristics that allow them to be identified as myxogastrids. Amoeboflagellates rather than plasmodia were recorded, since the former are the forms present in soil.

Populations of soil protozoa (ciliates, various soil amoebae and myxogastrids) were assessed by the most probable number (MPN) technique, using tables for five replicates and tenfold dilution series. Numbers of positive records per dilution series generally conformed to the expected levels of abundance in all samples and, therefore, significant differences were covered by a $\log _{10}$ confidence limit (Taylor 1962). The ten-fold dilution series with five replicates at each concentration of soil resulted in MPN tables giving counts up to $>16,000$ per $\mathrm{cm}^{3}$. As already noted, the counts were of (1) fresh soil with active and easily excysted amoebae and of (2) frozen soil with only freeze-activated cysts.

Populations of Serratia marcesens were assessed by the plate-dilution method using plate count agar (Oxoid CM35, Oxoid Ltd., Basingstoke, United Kingdom) containing $1.0 \%$ (v/v) added sterile soil extract (Feest \& Madelin 1985b). Colonies, identified from their deep pink colour, were counted after incubation for $48 \mathrm{hr}$ at $20^{\circ} \mathrm{C}$. The populations of total bacteria were counted on the same plates. Soil moisture was determined gravimetrically after drying in a circulating air oven at $85^{\circ} \mathrm{C}$ for 7 days. Dalapon residues in soil were extracted and determined as described by Cotterill (1975) from samples taken using a corer to a depth of $18 \mathrm{~cm}$.

\section{Results}

Field Experiment: The numbers of $S$. marcesens present in the soil rose markedly immediately after application but, by the next day, had declined to a level only slightly higher than the beginning level. Numbers then stayed at this low level throughout the experiment (Table 1). Initially, all of the field soil samples taken, contained more trophic myxogastrids than encysted forms. As a result, the encystment index was more than 1 (Table 2). Within the first day after treatment, the overall numbers and, especially, the proportion of trophic forms rose sharply in all plots except for the control. Then, just as quickly, they declined during the second day, with the resulting low numbers of trophic forms and the ratio of trophic to encysted forms persisting to the end of the experiment. Similar results were observed for both amoebae and ciliates (Table 2) 
Table 1 Populations (x $10^{7} \mathrm{~g}^{-1}$ dry soil) of total bacteria and Serratia marcesens in field soil.

\begin{tabular}{ccccc}
\hline Time (days after Treatment) & \multicolumn{4}{c}{ Treatment } \\
\hline & Control & Water & Dextrose & Bacteria* \\
1 & 2.86 & 6.56 & 4.63 & $5.17(<0.10)$ \\
2 & 7.45 & 9.80 & 21.50 & $6.90(46.90)$ \\
3 & 3.00 & 12.40 & 10.40 & $39.90(0.85)$ \\
\hline
\end{tabular}

*Figures in parentheses are for S. marcesens.

except that in the latter case, there was no flush of trophic forms immediately after treatment. The proportion of trophic ciliates generally declined throughout the sampling period from the first sample onwards.

Mesocosm Experiment: In the mesocosm experiment, concentrations of Dalapon in the top 1 $\mathrm{cm}$ of the treated soils immediately ( $<1$ hour) after spraying were $138 \mu \mathrm{g} \mathrm{g}^{-1}$ and $14.1 \mu \mathrm{g} \mathrm{g}^{-1}$ for the 40 and $4 \mathrm{~kg} \mathrm{ha}^{-1}$ application rates, respectively. No herbicide could be detected below this soil layer at that time. It should be noted that at this point in the experiment, rain was falling, and the boxes exposed to the rain showed the herbicide rapidly moving down the soil profile to such an extent that one day after treatment the concentrations in the top $10 \mathrm{~cm}$ were 10 and $<1 \mu \mathrm{g} \mathrm{g}^{-1}$, respectively, for the two applications. On subsequent days equivalent concentrations were 8,8 , and $5 \mu \mathrm{g} \mathrm{g}^{-1}$ for the $40 \mathrm{~kg}$ treatment. Concentrations in the $4 \mathrm{~kg}$ treatment and in the top $2 \mathrm{~cm}$ of the $40 \mathrm{~kg}$ treatment were too low $(<0.5 \mu \mathrm{g})$ to measure accurately after the first day following treatment.

Throughout the entire sampling period in the mesocosm experiment, the total population of myxogastrids remained relatively stable regardless of the treatment imposed on the soil (Table 3). Certainly, the addition of Dalapon to the soil, even in very a high dose, produced no significant response in the total population of protozoans. Only a few marked changes in population occurred, and these took place at irregular and unpredictable intervals. Even the onset of drought in the last period of the experiment, when the moisture content of the soil dropped to 15 to 19 percent (Table 5), produced little change in the populations of protozoans present. Furthermore, drought had no major impact on the ratio of trophic to encysted forms.

Table 2 Populations $\left(\mathrm{x}_{10} \mathrm{~cm}^{3}\right.$ dry soil) of trophic and encysted protozoans in field soil.

\begin{tabular}{|c|c|c|c|c|c|c|c|c|c|c|}
\hline \multirow{2}{*}{ Treatment } & \multirow{2}{*}{$\begin{array}{c}\text { Time } \\
\text { (DAT)* }\end{array}$} & \multicolumn{3}{|c|}{ Myxogastrids } & \multicolumn{3}{|c|}{ Amoebae } & \multicolumn{3}{|c|}{ Ciliates } \\
\hline & & Trophic & Cysts & $\mathbf{T} / \mathrm{C}$ & Trophic & Cysts & $\mathrm{T} / \mathrm{C}$ & Trophic & Cysts & $\mathbf{T} / \mathbf{C}$ \\
\hline \multirow[t]{4}{*}{ Control } & 0 & 1.10 & 0.25 & 4.4 & 5.50 & 1.70 & 3.9 & 0.14 & 0.07 & 2.0 \\
\hline & 1 & 0.40 & 0.11 & 3.6 & 9.00 & 0.70 & 12.9 & 0.25 & 0.11 & 2.3 \\
\hline & 2 & 0.04 & 0.04 & 1.0 & 0.80 & 0.25 & 3.2 & 0.17 & 0.17 & 1.0 \\
\hline & 3 & 0.14 & 0.50 & 0.3 & 0.80 & 0.50 & 1.6 & 0.08 & 0.25 & 0.3 \\
\hline \multirow[t]{4}{*}{ Water } & 0 & 0.50 & 0.17 & 2.9 & 5.50 & 3.50 & 1.6 & 0.17 & 0.07 & 2.4 \\
\hline & 1 & 0.95 & 0.08 & 11.9 & 3.50 & 0.25 & 14.0 & 0.13 & 0.11 & 1.2 \\
\hline & 2 & 0.11 & 1.10 & 0.1 & 0.50 & 5.50 & $<0.1$ & 0.25 & 0.17 & 1.5 \\
\hline & 3 & 0.17 & 1.70 & 0.1 & 0.80 & 3.50 & 0.2 & 0.07 & 0.50 & 0.1 \\
\hline \multirow[t]{4}{*}{ Dextrose } & 0 & 0.20 & 0.09 & 2.2 & 5.50 & 1.40 & 3.9 & 0.80 & 0.02 & 40.0 \\
\hline & 1 & 1.10 & 0.02 & 55.0 & 5.50 & 0.25 & 22.0 & 0.50 & 0.13 & 3.8 \\
\hline & 2 & 0.15 & 1.30 & 0.1 & 2.50 & 2.50 & 1.0 & 0.25 & 0.13 & 1.9 \\
\hline & 3 & 0.35 & 5.50 & $<0.1$ & 0.35 & 5.50 & $<0.1$ & 0.11 & 0.25 & 0.4 \\
\hline \multirow[t]{4}{*}{ Bacteria } & 0 & 0.70 & 0.35 & 2.0 & 5.50 & 5.50 & 1.0 & 0.04 & 0.14 & 0.3 \\
\hline & 1 & 1.70 & 0.13 & 12.8 & 5.50 & 0.50 & 11.0 & 0.50 & 0.25 & 2.0 \\
\hline & 2 & 0.17 & 0.14 & 1.2 & 1.10 & 0.50 & 2.2 & 0.04 & 0.25 & 0.2 \\
\hline & 3 & 0.35 & 1.40 & 0.3 & 0.50 & 5.50 & $<0.1$ & 0.17 & 0.25 & 0.7 \\
\hline
\end{tabular}

*DAT $=$ Days after treatment; T/C is the ratio of trophic to encysted forms. 
Table 3 Populations (x $10^{3} \mathrm{~cm}^{3}$ dry soil) of trophic and encysted protozoans in mesocosm soils.

\begin{tabular}{|c|c|c|c|c|c|c|c|c|c|c|}
\hline \multirow{2}{*}{$\begin{array}{l}\text { Treatment } \\
\text { Control }\end{array}$} & \multirow{2}{*}{$\begin{array}{c}\begin{array}{c}\text { Time } \\
(\text { DAT)* }\end{array} \\
<0\end{array}$} & \multicolumn{3}{|c|}{$\begin{array}{r}\text { Myxogastrids } \\
\text { Trophic Cysts T/C }\end{array}$} & \multicolumn{3}{|c|}{$\begin{array}{c}\text { Amoebae } \\
\text { Trophic Cysts T/C }\end{array}$} & \multicolumn{3}{|c|}{$\begin{array}{c}\text { Ciliates } \\
\text { Trophic Cysts T/C }\end{array}$} \\
\hline & & 0.2 & 0.2 & 1.0 & 9.2 & 5.4 & 1.7 & 0.20 & 0.04 & 5.0 \\
\hline & 0 & 1.7 & 2.4 & 0.7 & 3.5 & 9.2 & 0.4 & 0.20 & 0.04 & 5.0 \\
\hline & 1 & 1.0 & 1.7 & 0.6 & 2.8 & 16.0 & 0.2 & 0.20 & 0.10 & 2.0 \\
\hline & 2 & 2.4 & 0.7 & 3.4 & 5.4 & 16.0 & 0.3 & 0.02 & 0.30 & 0.1 \\
\hline & 3 & 0.2 & 0.5 & 0.4 & 2.2 & 5.4 & 0.4 & 0.08 & 0.08 & 1.0 \\
\hline & 11 & 1.3 & 1.3 & 1.0 & 5.4 & 9.2 & 0.6 & 0.07 & 0.08 & 0.9 \\
\hline \multirow[t]{6}{*}{ Water } & $<0$ & 0.04 & 0.3 & 0.1 & 1.3 & 5.4 & 0.2 & 0.10 & 0.10 & 1.0 \\
\hline & 0 & 0.7 & 0.1 & 7.0 & 5.4 & 2.4 & 2.3 & 0.08 & 0.04 & 2.0 \\
\hline & 1 & 0.3 & 1.3 & 0.2 & 3.5 & 3.5 & 1.0 & 0.08 & 0.08 & 1.0 \\
\hline & 2 & 0.1 & 0.1 & 1.0 & 3.5 & 1.7 & 2.0 & 0.08 & 0.04 & 2.0 \\
\hline & 3 & 0.3 & 1.1 & 0.3 & 5.4 & 9.2 & 0.6 & 0.02 & 0.10 & 0.2 \\
\hline & 11 & 0.1 & 0.3 & 0.3 & 2.2 & 9.2 & 0.2 & 0.30 & 0.05 & 6.0 \\
\hline \multirow[t]{6}{*}{ Dalapon $4 \mathrm{~kg} \mathrm{ha}^{-1}$} & $<0$ & 2.4 & 0.1 & 24.0 & 9.2 & 9.2 & 1.0 & 0.5 & 0.07 & 7.1 \\
\hline & 0 & 0.1 & 1.1 & 0.1 & 9.2 & 5.4 & 1.7 & 0.1 & 0.20 & 0.5 \\
\hline & 1 & 0.8 & 1.7 & 0.5 & 9.2 & 18.0 & 0.5 & 0.2 & 0.08 & 2.4 \\
\hline & 2 & 1.4 & 3.5 & 0.4 & 9.2 & 9.2 & 1.0 & 0.1 & 0.20 & 0.5 \\
\hline & 3 & 0.5 & 1.4 & 0.4 & 9.2 & 16.0 & 0.6 & 0.1 & 0.10 & 1.0 \\
\hline & 11 & 0.3 & 0.3 & 1.0 & 3.5 & 9.2 & 0.4 & 0.3 & 0.10 & 3.0 \\
\hline \multicolumn{11}{|l|}{ Dalapon $40 \mathrm{~kg} \mathrm{ha}^{-}$} \\
\hline & $<0$ & 0.3 & 1.0 & 0.30 & 5.4 & 16.0 & 0.3 & 0.3 & 0.5 & 0.6 \\
\hline & 0 & 1.7 & 1.1 & 1.50 & 2.2 & 5.4 & 0.4 & 0.2 & 0.1 & 2.0 \\
\hline & 1 & 1.1 & 1.3 & 0.90 & 5.4 & 5.4 & 1.0 & 0.2 & 0.1 & 2.0 \\
\hline & 2 & 0.2 & 3.5 & 0.06 & 2.2 & 18.0 & 0.1 & 0.2 & 0.1 & 2.0 \\
\hline & 3 & 0.8 & 2.4 & 0.30 & 3.5 & 5.4 & 0.6 & 1.7 & 0.1 & 17.0 \\
\hline & 11 & 1.1 & 1.1 & 1.00 & 16.0 & 3.5 & 4.6 & 0.5 & 0.2 & 2.5 \\
\hline
\end{tabular}

$* \mathrm{DAT}=$ Days after treatment; $\mathrm{T} / \mathrm{C}$ is the ratio of trophic to encysted forms.

Note: $<0=$ sample taken immediately before treatment.

In two of the Dalapon treatments there was an increase in encystment, which in the high dosage treatment resulted in the population being almost completely encysted on day $2(\mathrm{~T} / \mathrm{C}=$ 0.06), which represented $1 / 25^{\text {th }}$ of the ratio observed on day 0 . However, this was not reproduced in the water treatment. The changes in the encystment ratio indicated that there was a shift from trophic to encysted forms (and the reverse) at intervals in all treatments, but this could be correlated only to the high dosage Dalapon treatment or to sampling frequency.

Essentially similar results were obtained for the other protozoan groups examined, but these are less clearly apparent due to the heterogenous nature of the taxa involved. Numbers of myxogastrids remained relatively stable regardless of the treatment imposed on the soil (Table 3).

\section{Discussion}

The data outlined above indicate that myxogastrid amoeboflagellates do display a pattern of encystment that can be related to different types of soil amendments. In particular, the response to Dalapon was noteworthy. The highly complex nature of the soil microhabitat has long been a hindrance to attempts to define the interactions of protozoans in soil. To understand fully the activities of a protozoan population, the latter must be homogenous and undifferentiated with respect to feeding and edaphic adaptation. For example, Feest (1987) highlighted the different niches occupied by dictyostelid (cellular) and myxogastrid (acellular) slime moulds. However, heterogeneity and differentiation are the norm in natural protozoan populations. An alternative approach is to study a specialist group of protozoans which does exhibit distinct characteristics of homogeneity and non-differentiation. Myxogastrids appear to fulfill these requirements. Despite the 
Table 4 Populations of bacteria and fungi in mesocosm soils.

\begin{tabular}{|c|c|c|c|c|}
\hline $\begin{array}{c}\text { Time } \\
(\text { DAT)* }\end{array}$ & Control & Water & $\begin{array}{l}\text { Dalapon } \\
4 \text { kg ha }^{-1} \\
\end{array}$ & $\begin{array}{c}\text { Dalapon } \\
40 \mathrm{~kg} \mathrm{ha}^{-1}\end{array}$ \\
\hline \multicolumn{5}{|c|}{$\begin{array}{c}\text { Bacteria (cfu } \\
\times 10^{6} \mathrm{~g}^{-1} \text { dry soil) }\end{array}$} \\
\hline$<0$ & nd & nd & nd & nd \\
\hline 0 & 4.43 & 4.36 & 2.45 & 3.79 \\
\hline 1 & 6.21 & 4.66 & 4.83 & 6.47 \\
\hline 2 & 6.82 & 8.03 & 5.00 & 4.90 \\
\hline 3 & 9.53 & 7.04 & 7.36 & 7.52 \\
\hline 11 & 8.69 & 6.13 & 6.04 & 8.66 \\
\hline \multicolumn{5}{|c|}{$\begin{array}{l}\text { Fungi (cfu } \\
\quad \times 10^{5} \mathrm{~g}^{-1} \text { dry soil) }\end{array}$} \\
\hline$<0$ & 5.66 & 4.32 & 6.20 & 12.42 \\
\hline 0 & 6.26 & 5.47 & 6.67 & 3.47 \\
\hline 1 & 6.76 & 3.70 & 4.48 & 3.87 \\
\hline 2 & 9.53 & 4.63 & 4.72 & 5.45 \\
\hline 3 & 8.05 & 4.41 & 7.69 & 6.76 \\
\hline 11 & 1.13 & 0.79 & 1.14 & 1.04 \\
\hline
\end{tabular}

*DAT $=$ Days after treatment; nd $=$ no data.

Note: $<0=$ sample taken immediately before treatment.

abundance of the group in British soils, only three very closely related species, all in the genus Didymium, appear to be consistently present (Feest 1987). It should be noted that the definition of at least one of the species (Didymium bahiense Gottsb.) that has been reported is rather suspect (Nannenga-Bremekamp 1991, Ing 1999), so the actual species biodiversity of at least the dominant myxogastrids in soils appears to be very low. In general, members of this group of organisms are relatively easily identified, as is also the case for naked amoebae and ciliates, the two other groups included in the present study. The generally slight responses of these two groups to the treatments imposed could be argued as being the result of their taxonomic heterogeneity.

Table 5 Moisture contents of mesocosm soil.

\begin{tabular}{|c|c|c|c|c|}
\hline $\begin{array}{c}\text { Time } \\
(\text { DAT)* }\end{array}$ & Control & Water & $\begin{array}{l}\text { Dalapon } \\
4 \mathrm{~kg} \mathrm{ha}^{-1}\end{array}$ & $\begin{array}{l}\text { Dalapon } \\
40 \mathrm{~kg} \mathrm{ha}^{-1}\end{array}$ \\
\hline$<0$ & 23.94 & 22.69 & 20.82 & 25.63 \\
\hline 0 & 30.49 & 26.09 & 29.35 & 27.85 \\
\hline 1 & 27.49 & 27.24 & 27.55 & 24.92 \\
\hline 2 & 25.96 & 26.50 & 28.31 & 28.43 \\
\hline 3 & 25.54 & 24.08 & 22.37 & 27.61 \\
\hline 11 & 19.40 & 19.37 & 15.65 & 18.25 \\
\hline
\end{tabular}

*DAT $=$ Days after treatment.

Note: $<0=$ sample taken immediately before treatment.

Overall differences in populations of soil protozoans did not differ by more than one $\log 10$ so that a confident illustration of the effect of an amendment is not easy to show. Conversely, the encystment indices do provide evidence of the changes that take place. Landolt \& Stephenson (1995) carried out a series of field and laboratory experiments designed to assess the effects of the chemical insecticide diflubenzuron (Dimilin 25-W), which was being used to control the gypsy moth, on dictyostelids and bacteria in an upland forest of Eastern North America. They were unable to demonstrate that the application of the insecticide to an entire watershed had any measureable influence, either directly or indirectly, on these two components of the soil microbiota. As such, the results obtained for dictyostelids do not appear to be comparable to what was obtained for 
myxogastrids in the present study, albeit the high levels of herbicide used in the two types of experiments (40kg/h Dalapon).

The sampling method used (Feest \& Madelin 1985a) in the present study was devised to provide statistically acceptable replicate samples of a defined population based on soil volume rather than weight (since the latter will vary according to soil density, which means that samples are not comparable). This is something that is rarely achieved by many other sampling procedures reported in the literature. However, it could be argued that such an intense sampling procedure applied to a relatively small area of soil might impose effects on the population being sampled. This might be a particular risk with populations of delicate organisms. Although, in some cases in the present study, there was a shift in the proportion of encysted forms of myxogastrids, amoebae and ciliates immediately after sampling, this was not consistent enough to allow interpretation as a direct result of the sampling procedure. For example, in the field experiment, the sample taken immediately after sampling the treated soils showed marked increases in the trophic/cyst ratio resulting from increases in the numbers of trophic amoeboflagellates and decreases in those of encysted forms. However, no such shift was apparent in the control, which was sampled in precisely the same way.

It is difficult to ascribe these changes to treatment. For example, treatment with water appears to have caused a much smaller increase in the ratio of trophic to encysted forms than was the case for the treatment with the dextrose solution. As dextrose would be expected to cause the bacterial population to increase markedly, and the latter represents the food source for protozoans, this would seem to be the expected result. However, the actual numbers of trophic amoeboflagellates was little different in the two treatments. The difference in the ratio that does exist arises from the lower number of cysts in the dextrose treatment, and this was present before treatment.

Although it is often claimed that herbicides are likely to cause serious damage to soil fertility as a result of having a negative effect on the essential soil microflora, the data presented herein show no detectable lasting influence of Dalapon, even at a high dose rate, on the protozoan groups examined. This was true both in terms of actual numbers of the different forms as well as the T/C ratio. Nor was any effect evident for soil fungi or, as reported for undisturbed soils by Wingfield et al. (1977), on bacteria.

In summary, the data obtained in the present study did not determine conclusively that myxogastrids are more sensitive detectors of environmental impact than other groups of protozoans. This is likely to be a result of the inherent heterogeneity of these groups. However, the present study has confirmed that myxogastrids are easy to detect and identify and, as a result, may serve as useful indicators of protozoan responses to soil perturbation. Certainly, they indicated a sensitivity to high herbicide levels. This requires verification, perhaps using pesticides, or other chemical or environmental manipulations of soil that are more likely to cause major effects on protozoans.

Of particular importance in the interpretation of soil protozoan studies is the effect of freezing soil samples upon excystment, something which does not occur with fresh soil samples. This can lead to gross underestimation of protozoan levels (in our experiment 1/25 of the actual population would have been recorded), thus making experiments invalid without incorporating the freezing treatment. Indeed, the only certain population number is the post-freezing population, since the fresh sample will include both active trophic forms and an undetermined proportion of activated encysted forms. As such, in future studies estimation of encysted forms following freezing definitely should be included.

\section{References}

Anderson RV, Elliot ET, McClellan JF, Coleman DC, Hunt HW. 1978 - Trophic interactions in soils as they effect energy and nutrient dynamics. III. Biotic interactions of bacteria, amoebae and nematodes. Microbial Ecology 4, 361-371. 
Chakraborty S, Old KM. 1982 - Mycophagous soil amebae - interactions with 3 plant pathogenic fungi. Soil Biology and Biochemistry 14(3), 247-255.

Clarholm M. 1985 - Interactions of bacteria, protozoa and plants leading to mineralization of soil nitrogen. Soil Biology and Biochemistry 17(2), 181-187.

Cole CV, Elliot ET, Hunt HW, Coleman DC. 1978 - Trophic interactions in soils as they effect energy and nutrient dynamics. V. Phosphorus transformations. Microbial Ecology 4, 381387.

Coleman DC, Cole CV, Hunt HW, Kelin DA. 1978a - Trophic interactions in soils as they affect energy and nutrient dynamics. I. Introduction. Microbial Ecology 4, 345-349.

Colinas C, Ingham E, Molina R. 1994 - Population responses of target and non-target forest soil organisms to selected biocides. Soil Biology and Biochemistry 26(1), 41-47.

Cotterill EG. 1975 - Determination of residues of Dalapon in soil by gas - chromatography. Journal of Chromatography 106(2), 409-411.

Ekelund F. 1999 - The impact of the fungicide fenpropimorph (Corbel R)) on bacteriovorous and fungivorous protozoa in soils. Journal of Applied Ecology 36(2), 233-243.

Feest A. 1987 - The quantitative ecology of soil Mycetozoa. Progress in Protistology 2, 331-361.

Feest A, Campbell R. 1986 - The microbiology of soils under successive wheat crops in relation to take-all disease. FEMS Microbiology Letters 38, 99-111.

Feest A, Madelin MF. 1985a. - A method for the enumeration of myxomycetes in soils and its application to a wide range of soils. FEMS Microbiology Ecology 31, 103-109.

Feest A, Madelin MF. 1985b - Numerical abundance of myxomycetes (myxogastrids) in soils in the West of England. FEMS Microbiology Letters 31(6), 353-360.

Feest A, Madelin MF. 1988a - Seasonal population changes of myxomycetes and associated organisms in four woodland soils. FEMS Microbiology Letters 53, 133-140.

Feest A, Madelin MF. 1988b - Seasonal population changes of myxomycetes and associated organisms in five non- woodland soils, and correlations between their numbers and soil characteristics. FEMS Microbiology Letters 53, 141-150.

Foissner W. 1997 - Protozoa as indicators in agroecosystems, with an emphasis on farming practices, biocides and biodiversity. Agricultural Ecosystems and Environment 62(2-3) 93103.

Gel'ser-Ju G, Geptner VA. 1976 - Protisticide effect of herbicides. Pedobiologia 16(3), 174-184.

Gupta VVSR, Germida JJ. 1988 - Populations of predatory protozoa in field soils after 5 years of elemental S-fertilizer application. Soil Biology and Biochemistry 20(6), 787-791.

Ing B. 1999 - The Myxomycetes of Great Britain and Ireland. Richmond Publishing, Slough, England.

Ingham ER, Coleman DC. 1984 - Effects of Streptomycin, Cyclohexamide, Fungizone, Captan, Carbofuran, Cygon and PCNB on soil microorganisms. Microbial Ecology 10, 345-358.

Kamono A, Meyer M, Cavalier-Smith T, Fukui M, Fiore-Donno A-M. 2013 - Exploring slime mould diversity in high-altitude forests and grasslands by environmental RNA analysis. FEMs Microbial Ecology 84, 98-109.

Kerr SJ. 1994 - Frequency of recovery of myxomycetes from soils of the northern United States. Canadian Journal of Botany 72(6), 771-778.

Landolt JC, Stephenson SL. 1995 - Soil bacteria and fungi. Pages 93-105 in Reardon RC (ed.), Effects of Diflubenzuron on Non-target Organisms in Broadleaf Forested Watersheds in the Northeast, USDA Forest Service FHM-NC-05-95.

Nannenga-Bremekamp NE. 1991 - A guide to temperate Myxomycetes. Biopress Bristol UK. 409p.

Petz W, Foissner W. 1989 - the effects of Mancozeb and Lindane on the soil microflora of a Spruce forest - A field study using a completely randomized block design. Biology and Fertility of Soils 7(3), 225-231.

Stephenson SL, Cavender JC. 1996 - Dictyostelids and myxomycetes. Pages 91-101 in Hall GS (ed.), Methods for the Examination of Organismal Diversity in Soils and Sediments. CAB 
International, Oxon, United Kingdom.

Stephenson SL, Rajguru SN. 2010 - Dictyostelid cellular slime moulds in agricultural soils. Mycosphere 1, 333-346.

Stephenson SL, Landolt JC. 2011 - Dictyostelids from aerial "canopy soil" microhabitats. Fungal Ecology 4, 191-195.

Stephenson SL, Feest A. 2012 - Ecology of soil eumycetozoans. Acta Protozoologica 51, 201-208.

Stephenson SL, Fiore-Donno A-M, Schnittler M. 2011 - Myxomycetes in soil. Soil Biology and Biochemistry 43, 2237-2242.

Taylor J. 1962 - The estimation of numbers of bacteria by tenfold dilution series. Journal of Applied Bacteriology 25, 54-61.

Taylor KM. 1987 - The ecology of myxomycetes within decaying wood. Unpublished $\mathrm{PhD}$ thesis, University of Bristol, United Kingdom.

Urich T, Lanzén A, Hudson DH, Schleper C, Schuster SC. 2008 - Simultaneous assessment of soil microbial community structure and function through analysis of the MetaTranscriptome. PLOs One: 3(6) e2527.

Wingfield GI, Davies HA, Greaves MP. 1977 - The effect of soil treatment on response of soil microflora to the herbicide Dalapon. Journal of applied Bacteriology 43(1), 39-46.

Yeates GW, Bamforth SS, Ross DJ, Tate KR, Sparling GP. 1991 - Recolonization of Methyl bromide sterilized soils under four different field conditions. Biology and Fertility of soils 11(3), 181-189. 